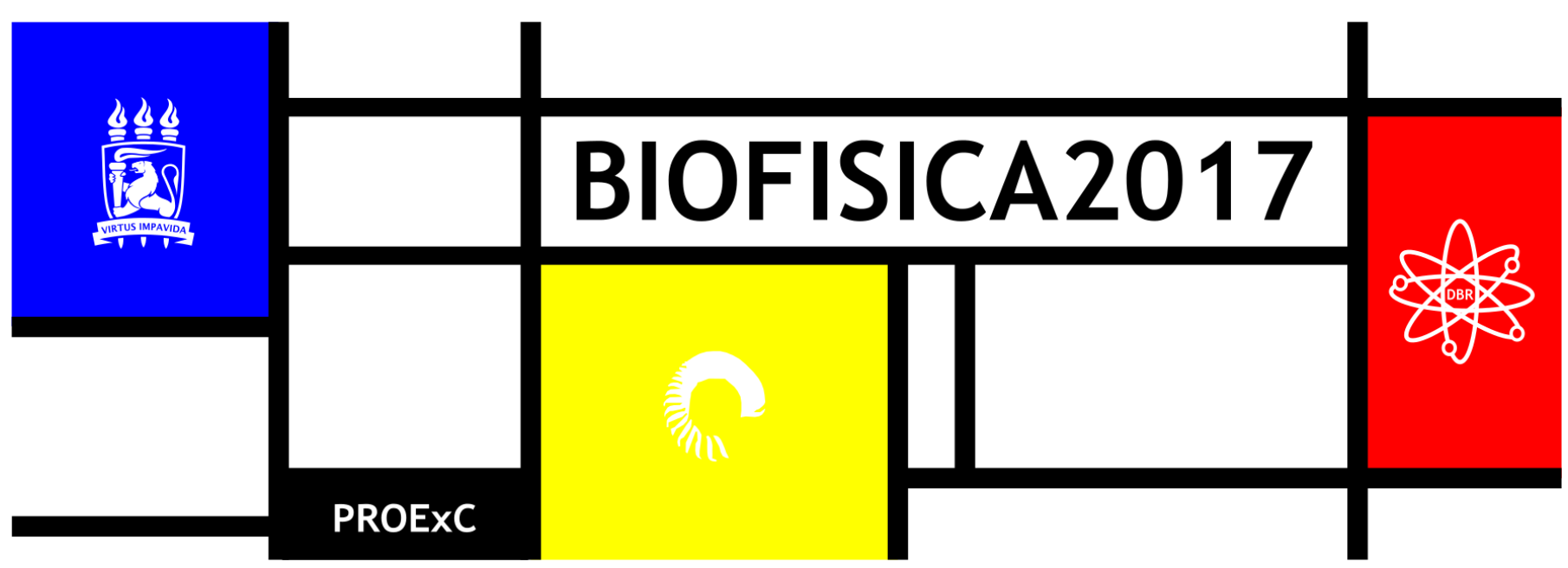

\title{
DESENVOLVIMENTO DE UM SISTEMA DE TRANSFERÊNCIA PARA CADEIRANTES
}

\author{
Paula Almeida dos Santos ${ }^{1}$, Vanessa Leandro dos Santos ${ }^{1}$, Alana Elza Fontes da Gama ${ }^{2}$, Clarisse \\ Lins de Lima², Hynglyson Lucas Ferreira Mendes², Jabson Heber Profiro de Oliveira ${ }^{3}$, Adriana \\ Fontes ${ }^{4}$ e Milton Marcelino Filho ${ }^{4 *}$
}

${ }^{1}$ Depto. de Fisioterapia-UFPE, ${ }^{2}$ Depto. de Engenharia Biomédica-UFPE, ${ }^{3}$ Programa de Pós-

Graduação em Inovação Terapêutica-UFPE, ${ }^{4}$ Depto. de Biofísica e Radiobiologia-UFPE

*milton.marcelinofo@ufpe.br

\section{INTRODUÇÃO}

De acordo com informações do censo de 2010, publicadas em 2012 pelo IBGE, aproximadamente 740 mil brasileiros possuem algum tipo de deficiência motora e declararam ser incapazes de caminhar (CARTILHA DO CENSO 2010-PESSOAS COM DEFICIÊNCIA, 2012). Entre diversas possibilidades de laudos, podemos exemplificar a paraplegia e tetraplegia como paralisias que impossibilitam um indivíduo de se locomover e até mesmo de realizar suas tarefas diárias com autonomia.

Tetraplegia refere-se à paralisia parcial ou total dos membros superiores, membros inferiores e do tronco e compromete também funções fisiológicas, a paraplegia refere-se à paralisia parcial ou total apenas dos membros inferiores e do tronco, também comprometendo funções fisiológicas.

Indivíduos tetraplégicos costumam ter lesões na coluna cervical abaixo da vértebra $\mathrm{C4}$, pois lesões localizadas acima desta vértebra interrompem a respiração levando o indivíduo a óbito. $\mathrm{Na}$ paraplegia as lesões ocorrem geralmente entre as vértebras $\mathrm{T} 1 \mathrm{e}$ T12 (FISIOTERAPIA NEUROLÓGICA, 2012).

A paraplegia pode ser de quatro tipos: a) flácida, com perda do tônus muscular, anestesia cutânea e anulação dos reflexos tendinosos; b) espástica, apresentando hipertonia muscular; c) reversíveis, causadas por doenças infecciosas curáveis ou compressão medular; d) irreversíveis, ocasionada por um corte transversal da medula ou problemas congênitos não curáveis (ABCMED, 2017).

Os indivíduos acometidos por paraplegia, através intervenções fisioterapêuticas e tratamento adequado, com o passar do tempo conseguem adquirir total independência para a realização das suas atividades diárias, desde que estejam devidamente acomodados em suas cadeiras de rodas. Mas, para serem transferidos da cama para a cadeira de rodas e vice-versa muitas vezes se faz necessário o auxílio de terceiros, sejam eles familiares ou cuidadores.

Atualmente há dois tipos de sistemas de transferência, o primeiro deles é a tábua de transferência, que consiste em um artefato de madeira, que pode ser utilizada por indivíduos que possuem força, habilidade e equilíbrio suficientes para realizar a passagem de um local para outro sobre a tábua, funcionando como uma espécie de ponte.

Este sistema, apesar de ser útil e possuir um baixo custo, apresenta um alto risco de queda para o cadeirante o que pode resultar em sérios problemas. 0 outro tipo de sistema é o guincho de transferência, porém os que são comercializados na atualidade necessitam da presença de um operador durante a utilização do equipamento para que seja realizada a devida transferência do cadeirante (CATÁLOGO NACIONAL DE PRODUTOS DE TECNOLOGIA ASSISTIVA, 2017).

Visando proporcionar uma melhor qualidade de vida e dar maior autonomia aos indivíduos com deficiência motora dos membros inferiores, este projeto teve como objetivo a elaboração de um sistema de transferência eletromecânico que possa ser operado apenas pelo cadeirante, ou seja, sem ajuda de terceiros e consequentemente thes proporcionando mais autonomia em suas tarefas cotidianas (VIVER SEM LIMITE, 2014).

\section{MATERIAIS E MÉTODOS}

O sistema de transferência desenvolvido é constituído de um guincho elétrico, que assegura o deslocamento para cima e para baixo, acoplado a um trole elétrico que move o guincho para a direita e para a esquerda apoiado em um trilho metálico, ambos comandados por um controle remoto, controlado pelo próprio cadeirante. Além dos componentes eletromecânicos, compõe o sistema de transferência um colete, no qual será acomodado o indivíduo a ser transportado da cama para a cadeira de rodas ou da cadeira de rodas para a cadeira de banho, sem a necessidade de ajuda de terceiros.

\section{Sistema Eletromecânico}

O sistema eletromecânico é constituído por um guincho com capacidade de carga de até $150 \mathrm{Kg}$, velocidade de elevação de $10 \mathrm{~m} / \mathrm{min}$, alimentado por tensão de $220 \mathrm{~V}$ monofásica. Acoplado ao guincho temos um trole com capacidade de até $300 \mathrm{~kg}$, velocidade 
de translação de $13 \mathrm{~m} / \mathrm{min}$, também alimentado por tensão de $220 \mathrm{~V}$ monofásica, ambos fabricados pela ACM TOOLS $®$, (Figura 1). $\mathrm{O}$ conjunto guincho-trole se move ao longo de um trilho, ou viga metálica, de perfil "I" apoiada em suas extremidades em suportes metálicos, os quais são fixados nas paredes laterais através de chumbadores mecânicos do tipo parabolt, posicionando-se transversalmente sobre a cama do cadeirante. Estes suportes são revestidos internamente por uma camada de borracha nos pontos que entram em contato com a viga, com o objetivo de oferecer um amortecimento, diminuindo assim os ruídos e as vibrações indesejáveis que ocorrem durante o deslocamento do conjunto guincho-trole.

O sistema possui sensores de fim de curso nas duas extremidades, assim, quando o conjunto guincho-trole alcança o fim do trilho ele é automaticamente desligado, mesmo que o usuário continue acionando o controle remoto, evitando o choque do conjunto de motores com a parede.

Tanto o acionamento do motor do guincho quanto o acionamento do motor do trole é realizado através de um controle remoto sem fios, com quatro teclas, direita-esquerda e sobe-desce. 0 controle remoto utiliza ondas de rádio na frequência de $315 \mathrm{MHz}$ e possui um interruptor liga/desliga que habilita 0 seu próprio funcionamento, atuando como um mecanismo de segurança, pois quando está desligado evita o acionamento indesejado dos motores.

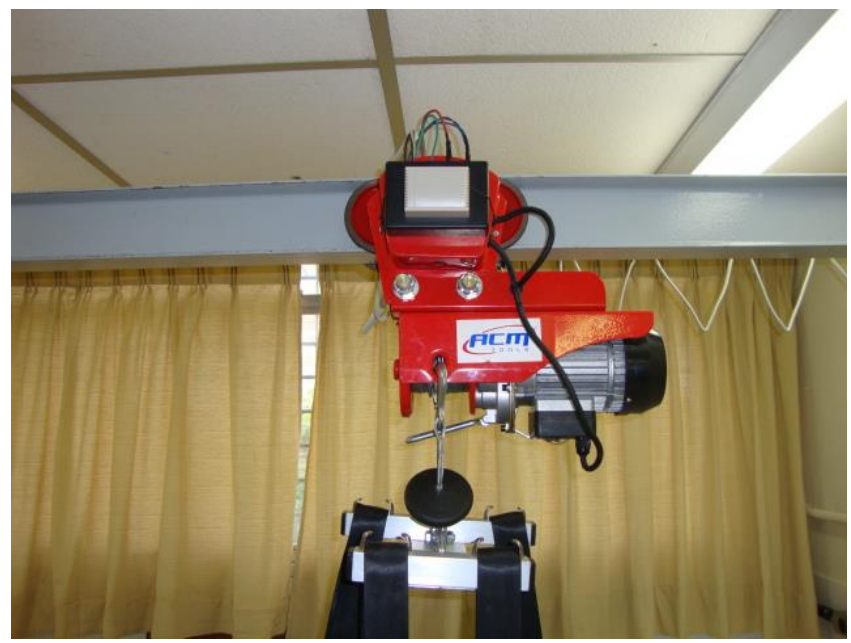

Figura 1. Trilho perfil "I"”, guincho, trole e cabide de sustentação do colete.

\section{Colete de Transferência}

O colete de transferência, também chamado de bolsa de transferência, foi projetado a partir de informações obtidas junto a membros da Associação dos Deficientes Motores de Recife (ADM), potenciais usuários, assim como de uma análise dos diferentes modelos existentes no mercado (Figura 2).

$\mathrm{Na}$ sua concepção e confecção, priorizou-se a segurança, a facilidade de utilização e o conforto do indivíduo. O colete foi confeccionado em Ripstop ${ }^{\circledR}$, tecido muito resistente, lavável e confortável ao contato, características estas importantes para o uso diário do cadeirante (TIRLONI; MORO, 2010; MOREIRA, 2015).

Em todas as partes do colete foram utilizadas duas camadas deste tecido, entremeadas por uma camada de espuma com espessura de $1,5 \mathrm{~cm}$. Este acolchoamento proporciona um bom conforto ao usuário.

O colete envolve o usuário pelas costas, por cima dos ombros e se estende até o quadril e região látero-posterior das coxas, envolvendo-as individualmente, formando assim uma espécie de cadeira. Para fixar o cadeirante ao colete, foi utilizada uma fita de poliéster de alta resistência, atendendo todas as normas técnicas da ABNT para cintos de segurança automotivos, com largura de $4,5 \mathrm{~cm}$, cor preta e capacidade de carga de 3 toneladas, sendo esta fixada lateralmente ao colete, na região correspondente ao tórax do usuário. O seu travamento é realizado através de uma fivela do tipo cinto de segurança automotivo. Este mesmo tipo de fita é utilizado para realizar a suspensão do indivíduo, sendo duas fitas na região do tórax (uma do lado direito e outra do lado esquerdo) e duas fitas nas extremidades inferiores do colete para suspensão das pernas (lado direito e lado esquerdo). As quatro fitas de suspensão possuem regulagem em seu comprimento, para ajustar-se às diferentes anatomias dos usuários e as suas extremidades são engatadas a um suporte de alumínio em forma de "H", o qual chamamos de cabide.

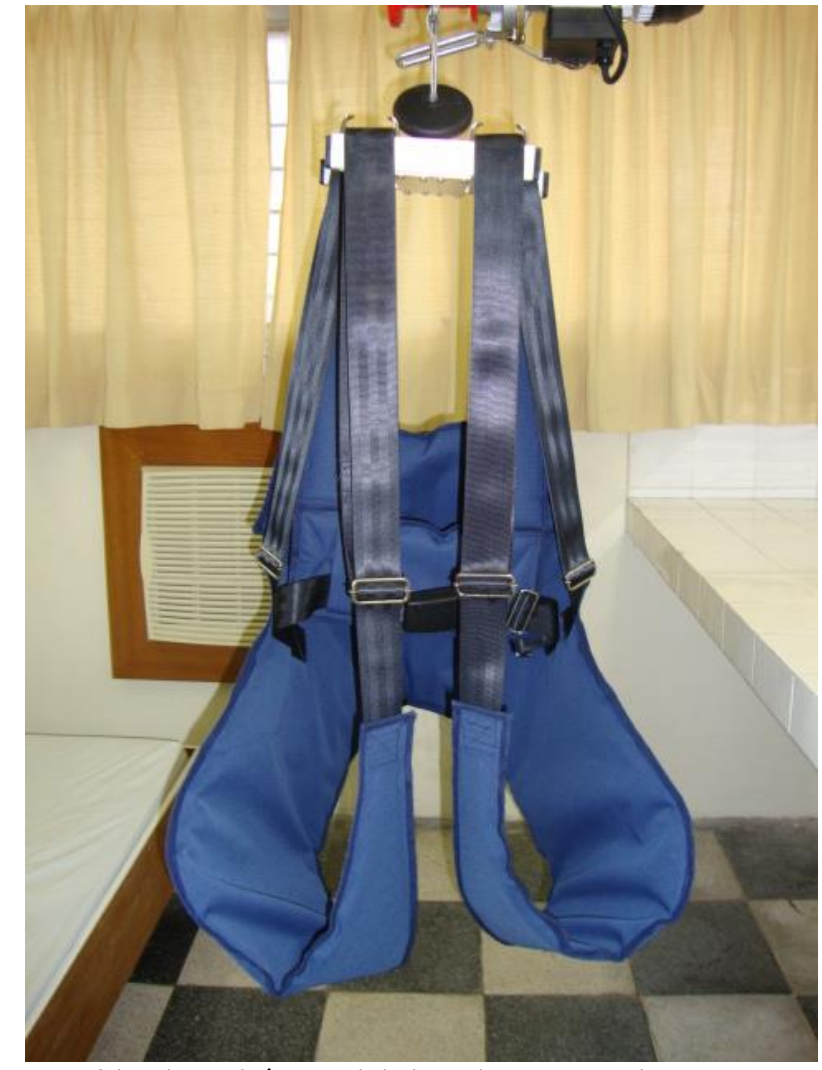

Figura 2. Colete de transferência e cabide de acoplamento ao guincho.

\section{RESULTADOS E DISCUSSÃO}

A Figura 3 apresenta uma imagem do sistema completo em uso, ou seja, realizando a transferência de um indivíduo da cadeira de rodas para a cama. O cadeirante após vestir o colete de transferência e acoplá-lo ao cabide, aciona o controle remoto, que nesta imagem pode ser visto na mão esquerda do indivíduo, e realiza os movimentos de elevação e translado. A transferência pode se dar também para uma cadeira de banho, caso ela esteja, por exemplo, do outro lado da cama.

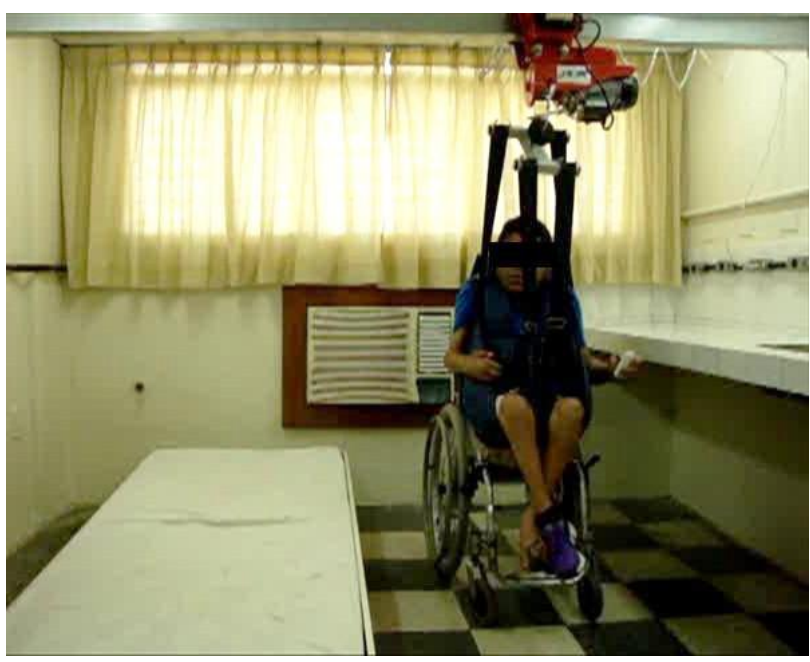

Figura 3. Sistema de transferência em uso. 
Vários testes foram realizados e o sistema de transferência mostrou-se eficaz e útil, atendendo aos objetivos propostos.

\section{CONCLUSÕES}

O desenvolvimento de dispositivos deste tipo não se limita apenas a devolver a autonomia ao cadeirante, mas também trazer uma melhora do bem estar integral do indivíduo no âmbito social e psicológico, confirmando a importância desse tipo de tecnologia assistiva no cotidiano das pessoas com limitações motoras.

\section{REFERÊNCIAS}

ABCMED - Informações Sobre a sua Saúde - Paraplegia: O que é? Quais os tipos e as causas? Como é o tratamento? Disponível em: <http://www.abc.med.br/p/348059/paraplegia+o+que+e+quais+os + tipos+e+as+causas+como+e+o+tratamento.htm $>$. Acesso em $02 \mathrm{de}$ Fevereiro de 2017.

CARTILHA DO CENSO 2010 - PESSOAS COM DEFICIÊNCIA, Luiza Maria Borges Oliveira, Secretaria de Direitos Humanos da Presidência da República (SDH/PR), Secretaria Nacional de Promoção dos Direitos da Pessoa com Deficiência (SNPD), Coordenação-Geral do Sistema de Informações sobre a Pessoa com Deficiência, 32 pág, Brasília, 2012. Disponível em: <http://www.pessoacomdeficiencia.gov.br/ app/sites/default/files/publicacoes/cartilha-censo-2010-pessoascom-deficienciareduzido.pdf>. Acesso em 02 de Fevereiro de 2017. CATÁLOGO NACIONAL DE PRODUTOS DE TECNOLOGIA ASSISTIVA, Ministério da Ciência e Tecnologia e Inovação - MCTI, no endereço: https://assistivaitsbrasil.wordpress.com/catalogo/. Acesso em 02 de Fevereiro de 2017.

FISIOTERAPIA NEUROLÓGICA - Diferença Entre Tetraplegia e Paraplegia. Disponível em: <http://neurologia.facafisioterapia.net /2012/03/diferenca-entre-tetraplegia-e.html>. Acesso em 02 de Fevereiro de 2017.

MOREIRA, L. F. DESENVOLVIMENTO DE VESTUÁRIO ERGONÔMICO PARA MULHERES PORTADORAS DE NANISMO. XI Semana de Extensão, Pesquisa e Pós-Graduação - SEPesq Centro Universitário Ritter dos Reis, 19 a 23 de outubro de 2015. Disponivel em: <https://www.uniritter.edu.br/files/sepesq/arquivos_trabalhos/36 11/702/930.pdf> Acesso em 02 de Fevereiro de 2017.

TIRLONI, A. S.; MORO, A. R. P. Interferência do vestuário no desempenho, na amplitude de movimento e no conforto na ginástica laboral. Rev Bras Cineantropom Desempenho Hum. v. 12, n. 6, p. 443-450, 2010.

VIVER SEM LIMITE - PLANO NACIONAL DOS DIREITOS DA PESSOA COM DEFICIÊNCIA, Luiza de Andrade Penido, Secretaria de Direitos Humanos da Presidência da República (SDH/PR), Secretaria Nacional de Promoção dos Direitos da Pessoa com Deficiência (SNPD), 180 pág, Brasília, 2014. Disponível em: <http://www.pessoacomdeficiencia.gov.br/app/sites/default/files /arquivos/\%5Bfield_generico_imagens-filefielddescription\%5D_0.pdf> Acesso em 02 de Fevereiro de 2017. 